\title{
Does the multiple-breath washout test need to be measured before spirometry?
}

\section{To the Editor:}

The multiple-breath washout (MBW) test is commonly used as an outcome measure in research studies, and evidence is accumulating in support of its clinical utility to identify early lung disease and monitor disease progression. At present, the MBW test is combined with traditional pulmonary function tests, such as spirometry. Forced expiratory manoeuvres may have the effect of mobilising secretions and could affect distribution of ventilation; therefore, MBW is conventionally performed prior to spirometry. In infants with lung disease, forced expiratory manoeuvres using the raised volume rapid thoracoabdominal compression technique were associated with a significant decrease in the lung clearance index (LCI) [1]. If these physiological effects are related to the forced expiratory manoeuvre, spirometry conducted in school-age children with cystic fibrosis (CF), in whom mucus plugging and inflammation are more pronounced, could likewise influence ventilation homogeneity and thus LCI. However, performing MBW prior to spirometry presents logistical challenges and may impede the implementation of MBW into clinical practice. Therefore, we conducted a prospective study to determine the effects of forced expiratory manoeuvres on MBW outcomes in school-age children.

Children between the ages of 6 and 18 years with CF, admitted to the hospital for treatment of acute pulmonary exacerbation, were enrolled. This inpatient study population was purposely selected to maximise the effects of forced expiratory manoeuvres. Pulmonary function tests were performed after 7 days of a 14-day course of intravenous antibiotic therapy, when symptoms returned to baseline, and at least $2 \mathrm{~h}$ after bronchodilator use. The study was approved by the Research Ethics Board of the Hospital for Sick Children (Research Ethics Board number 1000051399); informed consent or assent was obtained where applicable.

MBW measurements were performed using the EcoMedics Exhalyzer D (EcoMedics AG, Duernten, Switzerland) before and immediately after spirometry. Each participant performed MBW in an upright position, wearing a nose clip, breathing through a mouthpiece. MBW outcomes were reported if at least two technically acceptable trials were collected [2]. Spirometry was performed using the Easy on-PC (ndd Medizintechnik AG, Zurich, Switzerland) according to the criteria of the American Thoracic Society and European Respiratory Society [3]. Spirometry values were converted to \% predicted and z-scores using the Global Lung Function Initiative reference equations [4].

Characteristics of the study participants were reported as median and interquartile range (IQR) for continuous variables and frequency for categorical variables. Wilcoxon signed-rank tests were used to compare MBW outcomes before and after spirometry. A Bland-Altman plot was used to assess bias. Statistical analyses were performed using Stata 14.2 (StataCorp LLC, College Station, TX, USA).

15 children with CF (median (IQR) age 15.1 (13.4-16.8) years, 73\% female) completed the study. The study population had reduced lung function (median (IQR) forced expiratory volume in $1 \mathrm{~s} 73.4 \%$ (59.1-88.6\%) predicted) and lower body mass index (median (IQR) $23.7(17.6-48.7) \mathrm{kg} \cdot \mathrm{m}^{-2}$ ) compared to the overall CF population at our centre. Overall, there was no significant difference observed in LCI before and after spirometry (mean difference $0.04,95 \%$ CI $-0.54-0.63$; relative difference $-2.0 \%$ ). The magnitude of the difference was minimal, and within the variability of LCI observed within a test occasion (figure 1),

@ERSpublications

Spirometry does not have a short-term effect on multiple-breath washout outcomes, thus allowing greater flexibility for implementation into clinical practice http://ow.ly/2Tg330ngXk4

Cite this article as: Au JWY, McDonald R, Stanojevic S, et al. Does the multiple-breath washout test need to be measured before spirometry? ERJ Open Res 2019; 5: 00230-2018 [https://doi.org/ 10.1183/23120541.00230-2018].

Copyright (OERS 2019. This article is open access and distributed under the terms of the Creative Commons Attribution Non-Commercial Licence 4.0. 


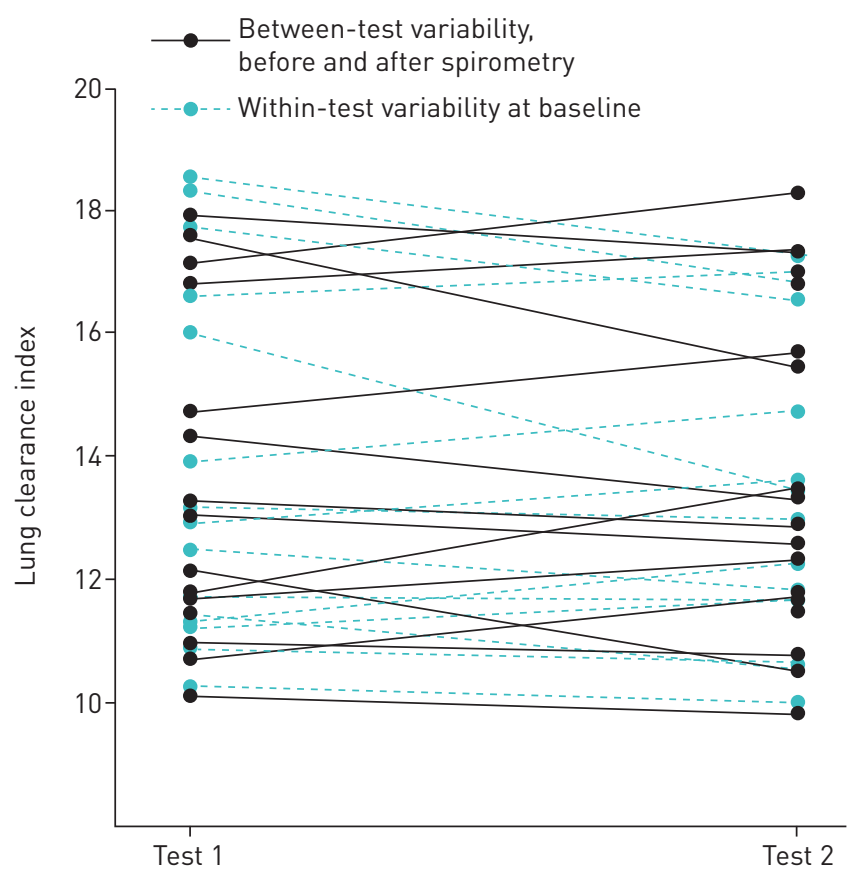

FIGURE 1 Comparison of the within-test variability of the lung clearance index (LCI) before spirometry (baseline) to the between-test variability (difference in $\mathrm{LCl}$ observed before and after spirometry). The between-test variability was within the variability observed within a test.

as well as within the previously reported between-test reproducibility of the test $( \pm 15 \%)$ in healthy preschool children [5] and stable school-age CF children [6]. Similar results were observed for functional residual capacity (mean difference $0.01 \mathrm{~L}, 95 \% \mathrm{CI}-0.05-0.08 \mathrm{~L}$; relative difference $1.9 \%$ ) and cumulative expired volume (mean difference $-0.11 \mathrm{~L}, 95 \% \mathrm{CI}-1.31-1.10 \mathrm{~L}$; relative difference $0.6 \%$ ).

The observed findings are consistent with a previous study that demonstrated no short-term effects of physiotherapy on MBW outcomes [7]. Although the patient population was specifically selected to represent patients with more pronounced mucus and inflammation (i.e. immediately following an acute worsening of symptoms requiring intravenous antibiotics), these results may not be generalisable to all patients seen at routine clinic visits. The sample size used for this comparison is limited; nonetheless, we do not wish to make inferences about the population. Indeed, to conduct a non-inferiority trial that the LCI measures within 0.04 units are not different, we would need a study sample size of $>1000$ subjects [8]. These data suggest that spirometry does not have a short-term effect on MBW outcomes in school-age children with $\mathrm{CF}$, thus allowing greater flexibility to implement MBW measurements into clinical practice.

Jacky W.Y. Au ${ }^{1}$, Reginald McDonald ${ }^{1}$, Sanja Stanojevic ${ }^{1}$ and Felix Ratjen ${ }^{1,2}$

${ }^{1}$ Translational Medicine, Research Institute, Hospital for Sick Children, Toronto, ON, Canada. ${ }^{2}$ Division of Respiratory Medicine, Hospital for Sick Children, Toronto, ON, Canada.

Correspondence: Felix Ratjen, Division of Respiratory Medicine, Hospital for Sick Children, 555 University Avenue, Toronto, ON, M5G 1X8, Canada. E-mail: felix.ratjen@sickkids.ca

Received: Nov 302018 | Accepted: Dec 182018

Conflict of interest: None declared.

Support statement: Funding was received from the Irwin Foundation. Funding information for this article has been deposited with the Crossref Funder Registry.

\section{References}

1 Subbarao $\mathrm{P}, \mathrm{Lu} \mathrm{Z}$, Kowalik $\mathrm{K}$, et al. Changes in multiple breath washout measures after raised volume rapid thoracoabdominal compression maneuvers in infants. Pediatr Pulmonol 2016; 51: 183-188.

2 Jensen R, Stanojevic S, Klingel M, et al. A systematic approach to multiple breath nitrogen washout test quality PLoS One 2016; 11: e0157523.

3 Miller MR, Hankinson J, Brusasco V, et al. Standardisation of spirometry. Eur Respir J 2005; 26: 319-338. 
4 Quanjer PH, Stanojevic S, Cole TJ, et al. Multi-ethnic reference values for spirometry for the 3-95-yr age range: the global lung function 2012 equations. Eur Respir J 2012; 40: 1324-1343.

5 Oude Engberink E, Ratjen F, Davis SD, et al. Inter-test reproducibility of the lung clearance index measured by multiple breath washout. Eur Respir J 2017; 50: 1700433.

6 Svedberg M, Gustafsson PM, Robinson PD, et al. Variability of lung clearance index in clinically stable cystic fibrosis lung disease in school age children. J Cyst Fibros 2018; 17: 236-241.

7 Fuchs SI, Toussaint S, Edlhaimb B, et al. Short-term effect of physiotherapy on variability of the lung clearance index in children with cystic fibrosis. Pediatr Pulmonol 2010; 45: 301-306.

8 Robinson PD, Lum S, Moore C, et al. Comparison of facemask and mouthpiece interfaces for multiple breath washout measurements. J Cyst Fibros 2018; 17: 511-517. 